\title{
Adoptive Cell Therapy Agent
}

National Cancer Institute

\section{Source}

National Cancer Institute. Adoptive Cell Therapy Agent. NCI Thesaurus. Code C142078.

A preparation of allogeneic or autologous cells that is meant to be administered to a

patient and may have a therapeutic effect. 